\title{
Long-term operation of Russian NPPs taking into account the actual loading of passive components
}

\author{
A.A. Arzhaev, K.A. Arzhaev, S.L. Butorin, I.N. Denisov, M.V. Konstantinov \\ arzhaev.alexander@yandex.ru | arzhaevk@insc.ru|butorin@insc.ru|denisov@insc.ru|west358@rambler.ru \\ ANO “International Nuclear Safety Center", Moscow, Russia
}

\begin{abstract}
The paper considers provision of strength and structural integrity for safety relevant passive NPP components pipelines and equipment - in long-term operation of NPP units. The methods of determining the actual load parameters during equipment installation, adjustment and commissioning are considered. The application of the acoustoelasticity method, which provides measurement of mechanical stresses arising as a result of technological operations, will allow to identify implicit installation preloads and assess their impact on ensuring the design life of pipeline systems, including the equipment installed. Recommendations are given for application of the acoustoelasticity method on NPP units under construction as a fist priority. At the objects of application of the acoustoelasticity method for the construction of the Unit 1 of Kursk NPP-2, noted above (ECCS, CS, steam and feed water pipelines), at the present time, in accordance with the certified measurement procedure (CMP), it is possible to reveal implicit installation preloads only at temperatures not higher than $55^{\circ} \mathrm{C}$. Monitoring the actual load level in the "as built" state will be a reliable guarantee of safe operation of Kursk NPP-2 pipelines according to the criteria of strength and structural integrity.
\end{abstract}

Keywords: long-term operation of nuclear power plants, service life management, structural integrity, pipelines and equipment, actual load level, acoustoelasticity method.

\section{Introduction}

Modern nuclear power plants (NPPs) of the Russian Federation with VVER-1200/1300 reactors belonging to generation III+ have a design life of at least 60 calendar years. Taking into account the fact that the performance of some of the passive elements of the NPP unit must be preserved in order to ensure the decommissioning of the power facility [1], the total service life is expected to be about 80 years. Current IAEA recommendations for NPP long-term operation (LTO) include development and implementation of special programs of lifetime management (LM) [2, 3].

The relationship between the processes of LM, aging management of NPP systems, structures and components (SSC) and ensuring or proof their structural integrity is shown schematically in Fig. 1 [4].

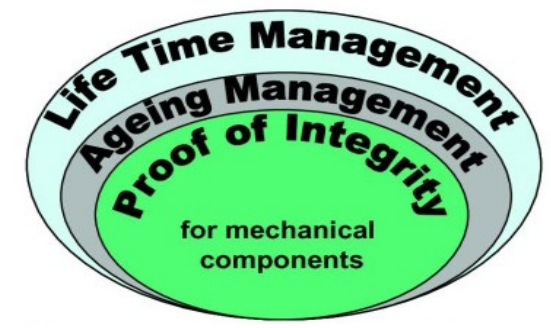

Fig. 1. The relationship between the processes of the life time management, SSC ageing management and proof of integrity for mechanical components

Ensuring the structural integrity of safety relevant passive NPP components (equipment and pipelines) is a modern tool for safe and cost-effective NPP LTO [5]

\section{Ensuring SSC structural integrity}

The measures to ensure structural integrity of NPP pipelines in accordance with GOST R 58328-2018 [6] include actual load monitoring (the requirement of mandatory Annex A) in addition to ensuring the specified lower limit of material impact strength at the end of the service life (the requirement of paragraph 1.2).

When selecting candidate piping systems the requirements of normative documents, for example, NP089-15 [7] are to be considered as well as , and the presence of characteristic aging degradation known from NPP operation experience as potential cause of piping break during LTO. It is also necessary to take into account the design characteristic features of SSC.

Dissimilar metals welds (DMW) are objects that are characterized by increased complexity in analyzing structural integrity and performance during LTO. To date, international programs are being conducted to study the characteristics of DMW operational reliability [8], and some research programs are planned for the period of years 2020-2025 [9].

Pipelines of pressure compensation systems (PCS) and emergency core cooling system (ECCS) adjacent to the VVER-1200/1300 reactor coolant circuit are made of austenitic steel and are connected to the circuit via DMW. To substantiate the integrity of these welded joints, it is necessary to know the actual load level of the PCS and ECCS pipelines.

Steam and feed water pipelines may be considered as additional objects of load control on NPP units with VVER-1200/1300 reactors as well as similar secondary circuit piping of VVER-1000 reactors due to their susceptibility to damages by the mechanism of flowaccelerated corrosion (FAC) [10].

Displacement control systems (DCS) are known as a tool to monitor the operational loads in pipeline systems. Effective DCS was implemented at unit 4 of the Kalinin NPP from the Unit commissioning. The same have been implemented at Units 3 and 4 of Rostov NPP and meets the requirements of paragraph 230 of NP-089-15 [7]. So DCS tested at the NPPs with VVER-1000 reactor can be recommended for use at the NPPs with VVER-1200/1300 reactors. The use of low-inertia ultrasonic sensors in DCS for fixing pipeline displacements increases the possibility of simultaneous monitoring of low-frequency vibrations 
and possible water hammer events (which differ from regular hydraulic tests according to NP-089-15), which can cause guillotine piping breaks, as known from NPP operation experience [11].

\section{Construction preloading monitoring}

However, the DCS can not detect the presence of additional loads in the pipeline system caused by preloading due to construction and equipment installation. Additional stresses due to preloading can be effectively revealed at the stage of construction of the NPP unit and installation of equipment. Taking into account the plans for the construction of NPPs in the Russian Federation, the nearest objects for monitoring the post-installation preloads during commissioning are candidate pipelines of ECCS, CS, steam and feed water at Unit 1 of Kursk NPP-2.

To control the post-installation stress-strained state (SSS) of NPP pipelines made of low-carbon and austenitic steels, the acoustoelasticity method can be used [12] in accordance with the CMP [13] approved for use at NPPs. The possibilities of the acoustoelasticity method application for monitoring stresses caused by installation preloads in order to ensure the alignment of NPP pipelines during welding are discussed in the papers $[14,15]$. The use of the acoustoelasticity method for monitoring the post-installation NPP pipeline SSS at Units under construction was supported in the scientific and technical council protocols of design organizations as early as 20132014 years.

The acoustoelasticity method is the only nondestructive method that allows measuring the values of axial and circumferential elastic stresses averaged over the wall thickness of the material in pipelines and thin-walled vessel shells [16]. This advantage is compromised by the fact that plastic deformations, internal defects, and other "imperfections" can distort the signal received during measurement. Therefore, both CMP [13] and GOST [17] explicitly indicate that measurements can only be made in the elastic region in the absence of plastic deformations. This restriction is a significant one. Usually component failures occurs after plastic deformation, and technical diagnostics in this area of deformations is of fundamental interest to the industry. Special technology is needed to reveal parts of the signal associated with such factors as:

- initial anisotropy of the material,

- mechanical stresses,

- plastic deformations,

- presence of defects inside the material.

Acoustoelasticity measurements are performed at a point. Ideally, when the pipe is loaded only by the tensile/ compressive axial forces, one point of measurement is sufficient. When a bend occurs, at least two diametrically opposite points in the plane of action of the bending moment are required. If the bending planes and the location of the points do not match, the measurement requires at least three evenly spaced points along the perimeter of the pipe, which allows you to restore the law of distribution of axial stresses.

However, this is suitable for the ideal case of absolutely accurate positioning of the measuring instrument and its zero error. The article [18] presents the results of measurements that indicate a significant dispersion of experimental data. Four measurement points are unrepresentative and can lead to large errors if there are defective metal zones or if one of the sensors fails. The optimal value should be recognized as six to eight measurement points located evenly along the perimeter of the pipe.

For a controlled cross-section (knowing at each point the measured stress value, wall thickness and, in addition, the perimeter of the pipe), it is possible to determine the axial force and components of the bending moment. In the simplest case of a straight section of the pipeline, when measuring in two extreme sections and there are no intermediate points of external force application (intermediate supports, tees, etc.), it is possible to restore the values of the components of the cutting force, i.e. the distribution of the bending moment along the pipe. The torque cannot be determined. On non-straight sections of the pipeline, measurements must be made in at least in three sections. These arguments are also suitable for areas with complex spatial geometry. Finally, only the mathematical expressions of the equilibrium equation become more complex.

If the conditions of applicability of the CMP [13] and GOST [17] are met, the acoustoelasticity method can be considered as an effective addition to section 5 of Annex 3 of the regulatory document PNAE G-7-002-86 [19], where the methods used in nuclear power engineering for experimental SSS determination of pipelines and equipment are described. The most widely used method of strain gauge measurement in the nuclear power industry makes it possible to measure SSS parameters only on the outer surface of pipelines and equipment.

The results of SSS measurements by acoustoelasticity method at the stages of installation and commissioning should be archived in the so-called information safety passport of the pipeline system, which should be further supplemented at the stages of operation, service life extension and decommissioning.

The method of acoustoelasticity does not allow to fix torques and cutting (lateral) forces near the closing (final) joint, so in the spatial system of pipelines, it is necessary to additionally monitor the value of those sections where additional bending moments can be detected from the cutting forces applied during welding of the closing (final) joint. Comparison of experimental data obtained at the stages of installation and commissioning of pipelines and NPP equipment with the results of design calculations will allow to correct the design calculation models and clarify the life time design estimates. Corrected calculation models and results of acoustoelasticity measurements must be archived in the pipeline system information safety passport.

\section{Results of field actual load monitoring}

For the period of years 2012-2015, the method of acoustoelasticity in accordance with the CMP [13] was applied on full-scale NPP elements only for the zones of the reactor coolant collector connection to the steam 
generator nozzle - "so called weld No.111" - at the NPPs with VVER-1000/1200 reactors. [20].

There was no experience of using the acoustoelasticity method in accordance with the CMP [13] during the same period of time for the control of mounting preloads during welding of the closing welded joints of NPP pipelines on the NPP units under construction.

Therefore, the success of the experience of applying the acoustoelasticity method in accordance with the CMP [13] at Russian NPPs can only be judged by the results of the work presented in article [20].

The article [20] analyzes the results of applying the acoustoelasticity method to reveal the causes weld No.111. Acoustoelasticity measurements were performed in the zone of weld No.111 (Fig. 2) [20, 21]

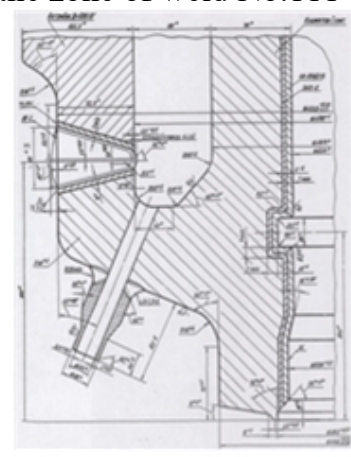

(a)

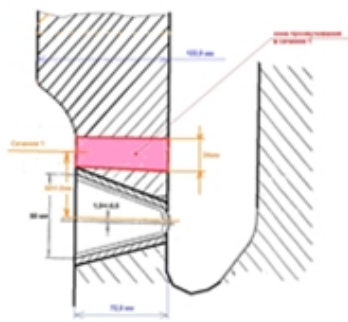

(b)
Fig.2. Zone of weld №111: (a) Junction of the collector with steam generator PGV-1000 nozzle; (b) Section of nozzle to collector zone for measuring by acoustoelasticity method (marked by red).

The paper [22] provided comments on the measurements reported in article [20]. It was noted that the zone (Fig.2) belong to a class of three-dimensional structures (Fig.3), in which the most problematic zone marked by red at Fig. 2 b) does not correspond to flat stress state conditions required for applying the calculation formulas used in CMP [13].

Therefore, it can be argued that the measurements made in the area indicated in Figure 2 (b) [20] can be treated only as expert estimates since they are obtained outside the scope of the conditions prescribed in the CMP [13]. The temperature range for performing measurements in the hydraulic test mode described in article [20] also does not correspond to the conditions for performing measurements in accordance with the CMP [13]. The error of measurements made with parameters outside the scope of the CMP certification [13] may significantly exceed the values recorded in the documents confirming the CMP certification.

\section{Relevance of the CMP revision}

The author's statement in article [20] that the results of the additional checks show that design features of the zone (Fig.2) and conditions of acoustoelasticity measurements (such as preliminary plastic deformation, preliminary cyclic loading, the quality of the back surface within the manufacturing tolerance of the steam generator, the presence of oxide films at the back surface, work in high temperatures) do not lead to exceeding the limits of error of measurement stated in CMP seems to be not valid enough. So official changes in the text of the CMP [13] or issuing of another document clarifying conditions of acousoelasticity method application to measurements at NPPs is evidently needed before its further application at the NPP.
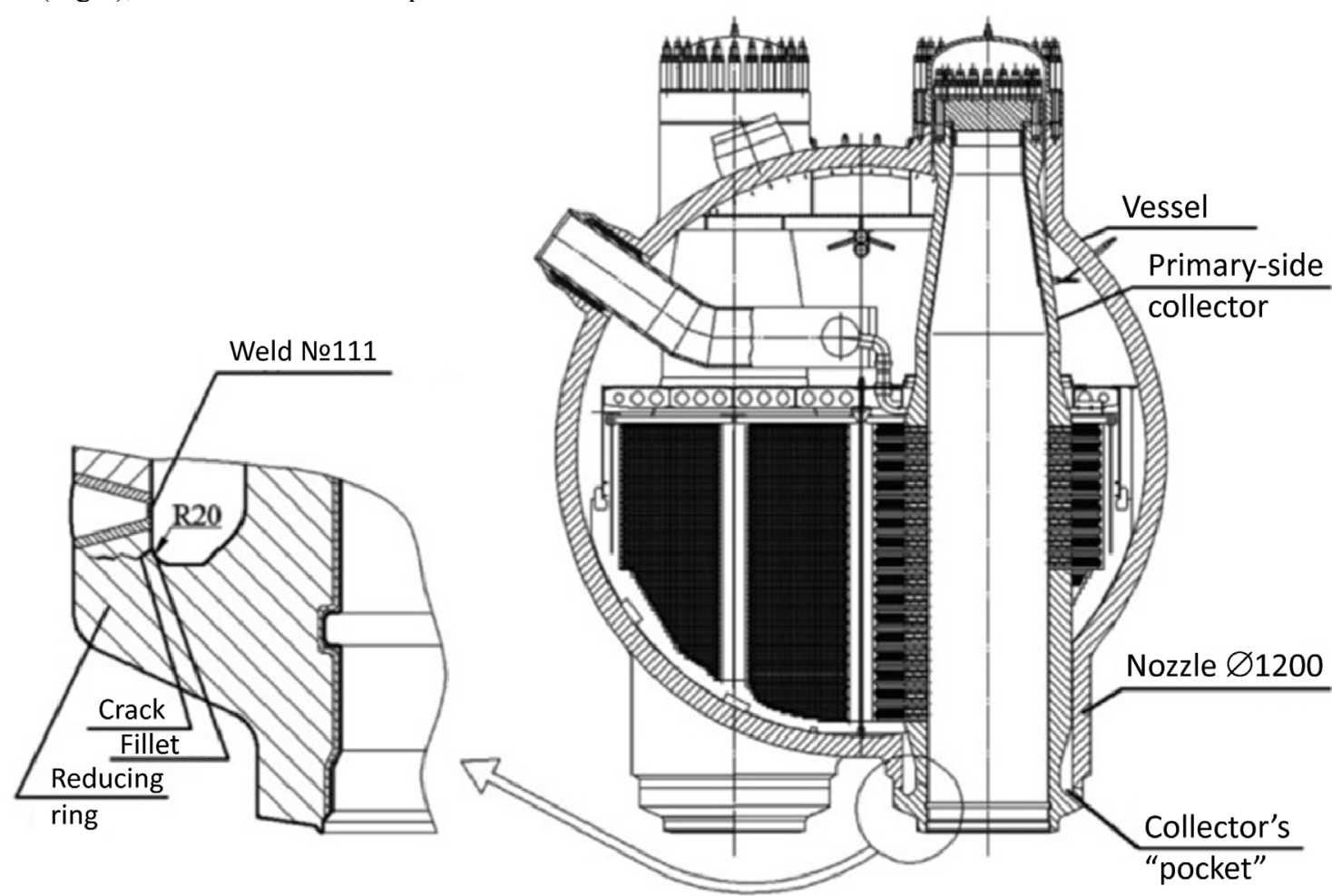

Fig.3. Steam Generator PGV-1000M 
However, the CMP adjustment [13] has not been performed to date, as evidenced by the CMP text published on the procurement website on the application of the acoustoelasticity method in the weld No.111 at Unit 2 of the Leningrad NPP-2 in the spring of 2020 year.

The latest achievements in the field of acoustic methods for measuring stresses in welded joints are reflected in patents [23-26], which creates the basis for the development in the coming years of appropriate CMPs suitable for use at NPPs during LTO.

\section{Conclusion}

At the objects of application of the acoustoelasticity method for the construction of the Unit1 of Kursk NPP-2, noted above (ECCS, CS, steam and feed water pipelines), at the present time, in accordance with the CMP [13], it is possible to reveal implicit installation preloads only at temperatures not higher than $55^{\circ} \mathrm{C}$.

Therefore, one of the immediate goals of improving the CMP [13] is to confirm the values of the acousto-elastic coupling coefficients for the temperature range of hydraulic tests, i.e. up to $130^{\circ} \mathrm{C}$.

Monitoring the actual load level in the "as built" state will be a reliable guarantee of safe operation of Kursk NPP-2 pipelines according to the criteria of strength and structural integrity.

\section{Acknowledgments}

The work was supported by the RFBR, grant 19-0700455

\section{References}

[1] NP-096-15. Requirements for management of service life of equipment and pipelines of nuclear power plants. General provisions.

[2] IAEA. Plant life management for long term operation of light water reactors. Principles and guidelines, 2006.

[3] IAEA. Plant life management models for long term operation of Nuclear Power Plants, 2015.

[4] Roos, E., Herter, K.-H., Kockelmann, H., Schuler, X. Proof of Integrity and Ageing Management of Mechanical Components in Nuclear Power Plants (SMiRT18-D01-4) // Proceedings of 18th International Conference on Structural Mechanics in Reactor Technology (SMiRT 18), Beijing, China, August 7-12, 2005.

[5] Arzhaev, A.A., Konstantinov, M.V., Makhanev V.O. et al. Regarding the role of plant equipment \& pipelines structural integrity concepts for safety justification and operating costs reduction // Tenth International Scientific and Technical Conference "Safety, efficiency and economics of nuclear power industry” (MNTK-2016). May 25-27, 2016, Moscow, Russia.

[6] GOST R 58328-2018. Piping of nuclear power plants. «Leak before break» concept, 2018.

[7] NP-089-15. Rules for Design and Safe Operation of Equipment and Pipelines of Nuclear Power Installations.
[8] NUREG/CR-7153. Expanded Materials Degradation Assessment (EMDA). Volume 1: Executive Summary of EMDA Process and Results. October 2014.

[9] Scott, P., Jenssen, A., Bjurman, M. et.al. SMILE Technical Project Description. January 23, 2020.

[10] Arzhaev, K., Butorin, S., Vopilkin, A., Tikhonov, D. et al. Complex management of FAC issues for operating and new NPP units // International conference on Flow Accelerated Corrosion (FAC2016), Lille, France, 2016.

[11]NEA (2017). Operating Experience Insights into Pressure Boundary Component Reliability and Integrity Management - Topical Report by the Component Operational Experience, Degradation and Ageing Programme (CODAP) Group. NEA/CSNI/R(2017)3. OECD, 2017.

[12] Nikitina, N.E. Acoustoelasticity Practical Exprience. N. Novgorod: TALAM, 2005. 208 p.

[13] LLC "INKOTES". Elements of NPP equipment. CMP mechanical stresses resulting from technological effects, the method of acoustoelasticity. FR.1.28.2009.06227.

[14] Butorin, S.L., Pasmanik, L.A., Podlatov, M.A. et al. About application of acoustoelesticity method for quality assurance of NPP piping assembling and repair // Eighth International Scientific and Technical Conference "Safety, efficiency and economics of nuclear power industry" (MNTK-2012). May 23-25, 2012, Moscow, Russia.

[15]Butorin, S.L., Makhanev, V.O., Podlatov, M.A. et al. Application of acoustoelesticity method for ensuring of safe operation of NPP technological components // Int. Conf. "Structural Integrity and Lifetime of NPP Equipment, Kiev, Ukraine, 2012.

[16]Pivkov A.V., Lobachev A.M., Polyanskiy V.A., Modestov V.S. Numerical simulation of ultrasonic waves in the isotropic elastic layer with the piezoelectric actuator // St. Petersburg Polytechnic University Journal - Physics and Mathematics. Peter the Great St. Petersburg Polytechnic University 2016. - №4 (253).

[17]GOST R 52890-2007. Non-destructive testing. Evaluation of stresses in material of pipelines by ultrasound. General requirements. Standardinform, 2009.

[18] Smirnov, V.A. Determination of the stress state of the material of the oil pumping unit pipes. - Book: Acoustoelasticity as a method of measuring mechanical stresses. Book edited by N.Nikitina. N.Novgorod: TALAM, 2010.

[19]PNAE G-7-002-86. Rules of strength calculation for equipment and pipelines of nuclear power plants.

[20] Modestov, V.S., Pasmanik, L.A. et al. Evaluation of stress-strain state JCP under thermal and force loading of steam generators PGV-1000 by means of the calculated-instrumental method with the definition of force boundary conditions by the acoustoelasticity method // Proceedings of the 9th international Scientific and Technical Conference "Safety 
assurance of NPP with VVER", May 19-22, 2015, Podolsk, Russia.

[21]Razygraev, A.N. Research and development of technology and tools for ultrasonic inspection of welded joints and assemblies of nuclear power equipment with limited access to inspection. Ph.D. Dissertation, Moscow, 2008, pp.115.

[22] Antonov, M.I., Arzhaev, A.I., Karyakin, Yu.E. Makhanev, V.O., Razygraev, N.P., Razygraev, A.N. Application of Acoustoelasticity Method for Ensuring Long-Term Service Life of NPP Engineering Elements // Eleventh International Scientific and Technical Conference "Safety, efficiency and economics of nuclear power industry" (MNTK-2018). May 23-24, 2018, Moscow, Russia.

[23]Patent 2589219 Russian Federation, Int.Cl. G01L $1 / 00$, G01N 29/04. Method of evaluating stress-strain state of elements of complex structures / Kamyshev, A.V., Pasmanik, L.A., Lukin, A.V., Popov, I.A., Pivkov, A.V., Modestov, V.S.; Proprietor OOO "INKOTES" - Application 2014133389/28; Date of filing 13.08.14; Date of publication 10.07.16.

[24]Patent 2648309 Russian Federation, Int.Cl. G01N 29/07. Method of determination of the contribution of plastic deformation to the amount of acoustic anisotropy in measuring of details of machines and elements of the design / Polyanskij, V.A., Grishchenko, A.I., Belyaev, A.K., Lobachev, A.M., Modestov, V.S., Semenov, A.S., Shtukin, L.V., Tretyakov, D.A., Yakovlev, Yu.A., Pivkov, A.V.; Proprietor IPMash RAN - Application 2016151104; Date of filing 23.12.16; Date of publication 23.03.18.

[25] Patent 2598980 Russian Federation, Int.Cl. G01N $29 / 04$. Ultrasonic method for determination of residual stresses in welded joints of pipelines / Kurashkin, K.V., Mishakin, V.V.; Proprietor IPMash RAN - Application 2014143229/28; Date of filing 27.10.14; Date of publication 10.10.16.

[26] Patent 2711082 Russian Federation, Int.Cl. G01N 29/07. Method for determination of residual stresses in weld metal welded joints of pipelines (versions) / Kamyshev, A.V., Pasmanik, L.A., Rovinskij, V.D., Getman, A.F., Guba, S.V.; Proprietors AO "Kontsern Rosenergoatom", OOO "INKOTES", AO "VNIIAES" - Application 2019110165; Date of filing 05.04.19; Date of publication 15.01.20.

\section{About the authors}

Alexander A. Arzhaev, lead engineer, ANO "International Nuclear Safety Center”. E-mail: arzhaev.alexander@yandex.ru. Kirill A. Arzhaev, reseacher, ANO "International Nuclear Safety Center”. E-mail: arzhaevk@insc.ru.

Sergey L. Butorin, first deputy director, Doctor of Technical Sciences, ANO "International Nuclear Safety Center". E-mail: butorin@insc.ru.

Ilya N. Denisov, deputy director, $\mathrm{PhD}, \mathrm{ANO}$ "International Nuclear Safety Center”. E-mail: denisov@insc.ru.

Maxim V. Konstantinov, lead reseacher, ANO "International Nuclear Safety Center”. E-mail: west358@rambler.ru. 